\title{
Identifikasi Tingkat Bahaya Bencana Longsor, Studi kasus: Kawasan Lereng Gunung Lawu, Kabupaten Karanganyar, Jawa Tengah
}

\author{
Nuri Iswoyo Ramadhani dan Hertiari Idajati \\ Jurusan Perencanaan Wilayah dan Kota, Fakultas Teknik Sipil dan Perencanaan, \\ Institut Teknologi Sepuluh Nopember (ITS) \\ Jl. Arief Rahman Hakim, Surabaya 60111 Indonesia \\ e-mail: hertiari_idajati@urplan.its.ac.id
}

\begin{abstract}
Abstrak-Kawasan yang berada di lereng Gunung Lawu, Kabupaten Karanganyar merupakan kawasan yang memiliki potensi terjadinya bencana tanah longsor. Frekuensi bencana longsor yang terjadi sekitar 300 pada 5 tahun terakhir. Bencana tersebut menyebabkan kerugian baik materiil maupun jiwa. Hal tersebut mengindikasikan kurangnya kewaspadaan dan kesiapan dalam menghadapi bencana. Karena kondisi yang berpotensi dan rawan maka perlu dikaji tingkat risiko bencana longsor sebagai upaya pemanfaatan lahan yang sesuai oleh masyarakat berdasarkan tingkat risiko yang berbeda. Penelitian ini bertujuan untuk merumuskan tingkat bahaya bencana longsor di lereng Gunung Lawu, Kabupaten Karanganyar. Artikel ini merupakan bagian dari penelitian pemetaan risiko bencana longsor di lereng Gunung Lawu, Jawa Tengah. Tahapan dalam mengetahui karakteristik bahaya yakni dengan pembobotan melalui AHP untuk analisis overlay weighted sum. Hasil dari penelitian ini berupa peta tingkat bahaya bencana longsor yang terbagi menjadi 3 klasifikasi dalam tingkatan bahaya bencana yakni tingkat bahaya rendah, bahaya sedang, dan bahaya tinggi.
\end{abstract}

Kata Kunci-Bencana longsor, Overlay weighted sum, Tingkat bahaya.

\section{PENDAHULUAN}

$\mathrm{I}_{\mathrm{b} e \mathrm{~s}}^{\mathrm{m}}$ NDONESIA merupakan salah satu negara yang rawan akan bencana. Menurut UU No. 24 Tahun 2007 tentang Penanggulangan Bencana, bencana ialah peristiwa atau rangkaian peristiwa yang mengancam dan mengganggu kehidupan dan penghidupan masyarakat yang disebabkan, baik oleh faktor alam dan/atau faktor nonalam maupun faktor manusia sehingga mengakibatkan timbulnya korban jiwa manusia, kerusakan lingkungan, kerugian harta benda, dan dampak psikologis. Bencana dapat dibedakan menjadi tiga antara lain bencana alam, bencana non alam dan bencana sosial [1].

Bencana tanah longsor merupakan gerakan masa batuan atau tanah pada suatu lereng karena pengaruh gaya gravitasi. Tanah longsor yang terjadi di Indonesia terjadi pada topografi terjal dengan sudut lereng sekitar $15^{\circ}-45^{\circ}$ dan pada batuan volkanik lapuk dengan curah hujan tinggi. Faktor penyebab terjadinya tanah longsor secara alamiah yakni morfologi permukaan bumi, penggunaan lahan, litologi, struktur geologi, curah hujan, dan kegempaan. Selain faktor alamiah, juga disebabkan oleh faktor aktivitas manusia yang mempengaruhi suatu bentang alam, seperti kegiatan pertanian, pembebanan lereng, pemotongan lereng, dan penambangan [2].

Di Provinsi Jawa Tengah terdapat 327 lokasi rawan longsor. Wilayah yang tergolong rawan bencana longsor yakni Banyumas, Banjarnegara, Purbalingga, Cilacap, Kebumen, Purworejo, Wonosobo, Tegal, Pemalang, Brebes, Pekalongan, Batang, Kendal, Semarang, Purwodadi, Pati, Jepara, Kudus, Magelang, Boyolali, Karanganyar, dan Wonogiri [3]. Kabupaten Karanganyar merupakan salah satu wilayah yang tergolong sering terjadi bencana tanah longsor di Provinsi Jawa Tengah. Hal tersebut dapat dilihat dari rata-rata frekuensi bencana yang terjadi di Kabupaten Karanganyar, dimana bencana tanah longsor memiliki frekuensi tertinggi yaitu 300 pada 5 tahun terakhir (BPBD Kabupaten Karanganyar, 2013)

Sedangkan berdasarkan intensitas bencana yang terjadi serta kerusakan yang mungkin ditimbulkan, bencana tanah longsor di Kabupaten Karanganyar dikategorikan menjadi 2 kawasan yakni bencana tanah longsor menengah dan tinggi. Bencana tanah longsor menengah memiliki kemiringan lereng 36-40\%. Sedangkan kemiringan lereng pada kawasan rawan bencana tinggi $>40 \%$ [4]. Di Kabupaten Karanganyar yang termasuk dalam kawasan rawan bencana tanah longsor tinggi yakni Ngargoyoso, Kecamatan Tawangmangu, Kecamatan Jatiyoso, Kecamatan Matesih, Kecamatan Jenawi, dan Kecamatan Kerjo [5].

Kejadian longsor terbesar pernah terjadi di Kecamatan Tawangmangu pada tahun 2007 di Desa Tengklik dan Desa Tawangmangu. Longsor yang terjadi di Desa Tengklik mengakibatkan 33 rumah roboh dan longsor di Desa Tawangmangu mengakibatkan 34 orang meninggal dunia [6].

Bencana longsor yang terjadi di Lereng Gunung Lawu Kecamatan Tawangmangu Kabupaten Karanganyar disebabkan oleh beberapa faktor yakni faktor geofisik (batuan, tanah, lereng) dan faktor aktivitas masyarakat terhadap penggunaan lahan serta intensitas hujan. Bencana tersebut menyebabkan kerugian baik materiil maupun jiwa (RTRW Kabupaten Karanganyar 2013-2032). Hal tersebut mengindikasikan kurangnya kewaspadaan dan kesiapan dalam menghadapi bencana. Sehingga perlu adanya peran serta masyarakat dalam menjaga lingkungan dan tentunya diperlukan kerjasama antara pemerintah dengan masyarakat dalam menanggulangi bencana longsor. Karena kondisi yang berpotensi dan rawan maka perlu dikaji tingkat risiko bencana longsor sebagai upaya memposisikan masyarakat pada daerah yang bersangkutan pada tingkat risiko yang berbeda. 


\section{METODE PENELITIAN}

\section{A. Metode Pengumpulan Data}

Metode pengumpulan data dalam penelitian ini terbagi menjadi dua primer dan sekunder. Primer melalui wawancara dengan stakeholder terkait untuk menentukan bobot masingmasing variabel. Sedangkan sekunder didapatkan melalui datadata dari dinas-dinas terkait.

\section{B. Variabel Penelitian}

Variabel penelitian merupakan turunan dari faktor yang bersifat kuantitatif maupun kualitatif. Berdasarkan tinjauan pustaka yang telah didapatkan, terdapat beberapa variabel penelitian terkait tingkat bahaya bencana longsor di kawasan lereng Gunung Lawu, Kabupaten Karanganyar. Berikut tabel variabel pada penelitian ini :

Tabel 1

Variabel Penelitian

\begin{tabular}{|c|c|c|c|}
\hline \multicolumn{4}{|c|}{ Variabel Penelitian } \\
\hline \multirow{7}{*}{$\frac{\text { Aspek }}{\text { Bahaya }}$} & Indikator & Variabel & Sumber \\
\hline & Penyebab & Curah hujan & $\begin{array}{ll}\text { Panduan } & \text { Pengenalan }\end{array}$ \\
\hline & \multirow{5}{*}{ Longsor } & Jenis tanah & Karakteristik Bencana \\
\hline & & Kelerengan & \multirow{3}{*}{$\begin{array}{l}\text { dan Upaya Mitigasinya } \\
\text { di Indonesia, } 2007 \\
\text { BAKORNAS PB, 2007, } \\
\text { Goenadi } \text { et al. }(2003)\end{array}$} \\
\hline & & Penggunaan lahan & \\
\hline & & $\begin{array}{l}\text { Jenis batuan dan } \\
\text { struktur geologi }\end{array}$ & \\
\hline & & Hidrologi & $\begin{array}{l}\text { Kementrian } \\
(2008)\end{array}$ \\
\hline
\end{tabular}

Sumber : Sintesa Tinjauan Pustaka, 2016

\section{Metode Analisis}

Analisis yang digunakan untuk mengetahui karakteristik bahaya di kawasan lereng Gunung Lawu adalah analisis AHP dan weighted overlay sum. Analisis pembobotan AHP ini dilakukan untuk menentukan prioritas variabel yang digunakan, yakni dengan menggunakan teknik perbandingan berpasangan yang diolah sehingga diperoleh bobot masing-masing variabel yang mempengaruhi. Pembobotan ini dilakukan dengan membagikan kuisisoner kepada beberapa stakeholder yaitu pemerintah, swasta dan masyarakat untuk mengetahui pembobotan pada variabel bahaya. Sedangkan metode weighted overlay, metode analisis ini merupakan analisis spasial dengan menggunakan teknik overlay beberapa peta yang berkaitan dengan faktor-faktor yang berpengaruh terhadap penilaian bahaya. Alat analisis yang digunakan adalah dengan menggunakan Geographic Information System (GIS) [7].

\section{HASIL DAN PEMBAHASAN}

\section{Karakteristik bahaya di kawasan Lereng Gunung Lawu Kabupaten Karanganyar}

Analisis yang digunakan untuk mengetahui karakteristik bahaya di kawasan Lereng Gunung Lawu Kabupaten Karanganyar adalah analisis AHP dan Overlay Weighted Sum. Tahapan pertama yakni dilakukan proses pembobotan pada variabel bahaya. Pembobotan tersebut diperoleh melalui proses wawancara dengan stakeholder terkait sesuai keahlian bidangnya. Adapun hasil dari pembobotan masing-masing variabel sebagai berikut :

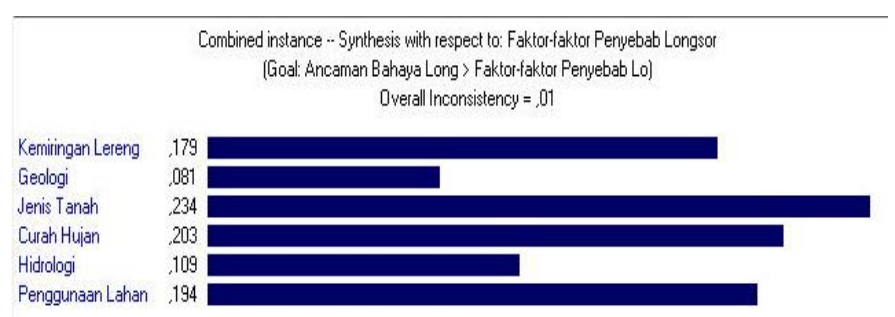

Gambar 1 Hasil AHP pembobotan variabel dalam faktor penyebab longsor Sumber : Analisis, 2016

Berdasarkan hasil analisis yang diatas, menunjukkan bahwa variabel-variabel dari faktor penyebab longsor adalah jenis tanah $(0,234)$, curah hujan $(0,203)$, penggunaan lahan $(0,194)$, kemiringan lereng $(0,179)$, hidrologi $(0,109)$, geologi $(0,081)$. Hasil analisis ini sudah dinyatakan valid dengan nilai inconsistency 0,01. Hal ini menunjukkan bahwa hasil wawancara yang dilakukan telah konsisten jawabannya sehingga analisisnya dapat dilanjutkan ke tahap selanjutnya. Berikut peta dari masing-masing variabel dari faktor-faktor penyebab longsor :
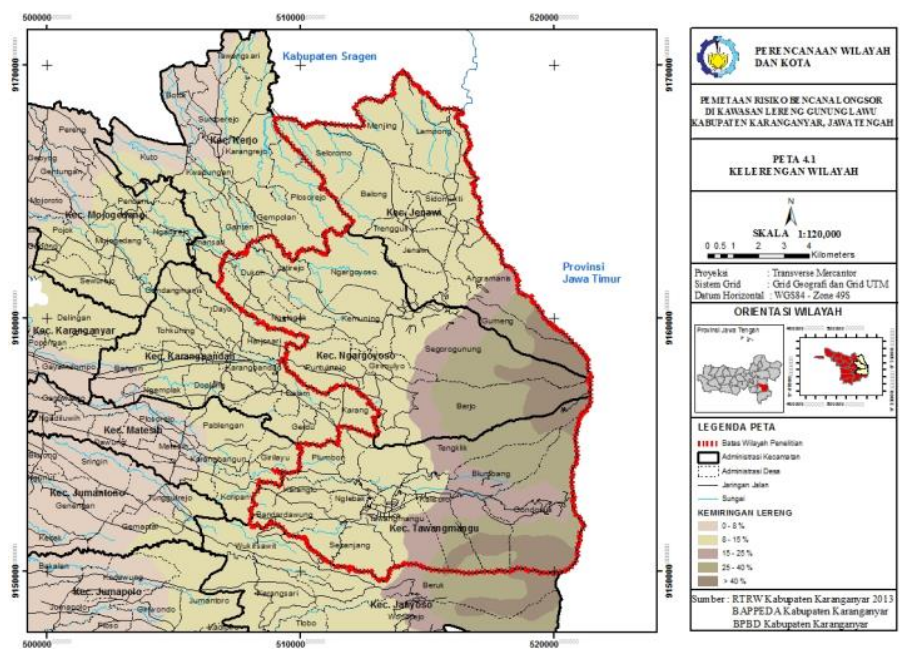

Gambar 2 Kelerengan Wilayah

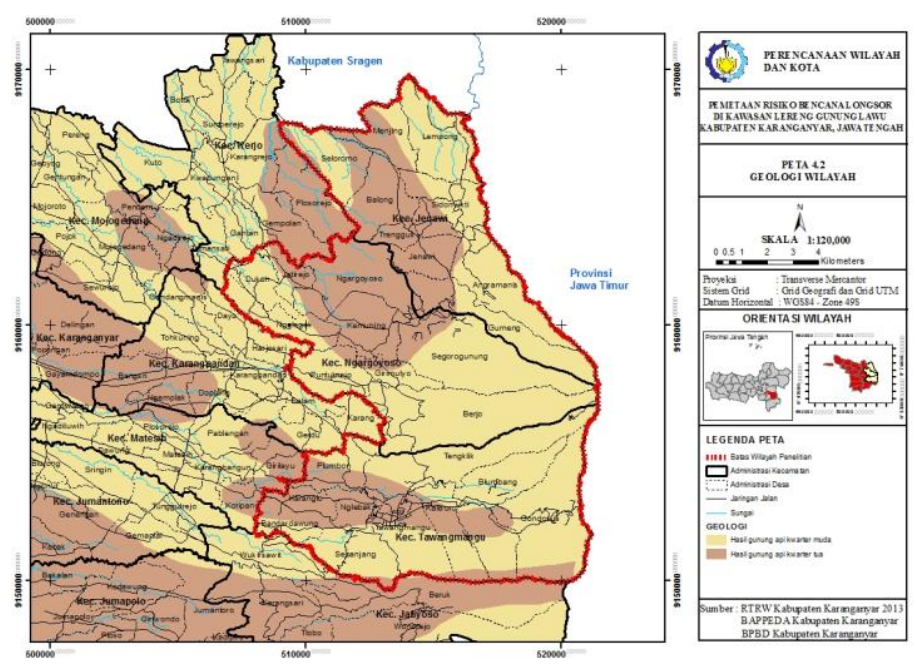

Gambar 3 Geologi Wilayah 


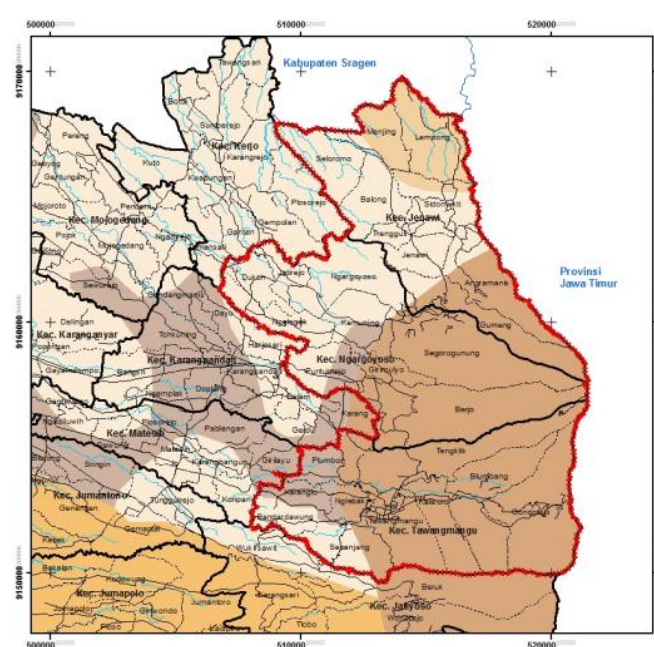

Gambar 4 Jenis Tanah Wilayah

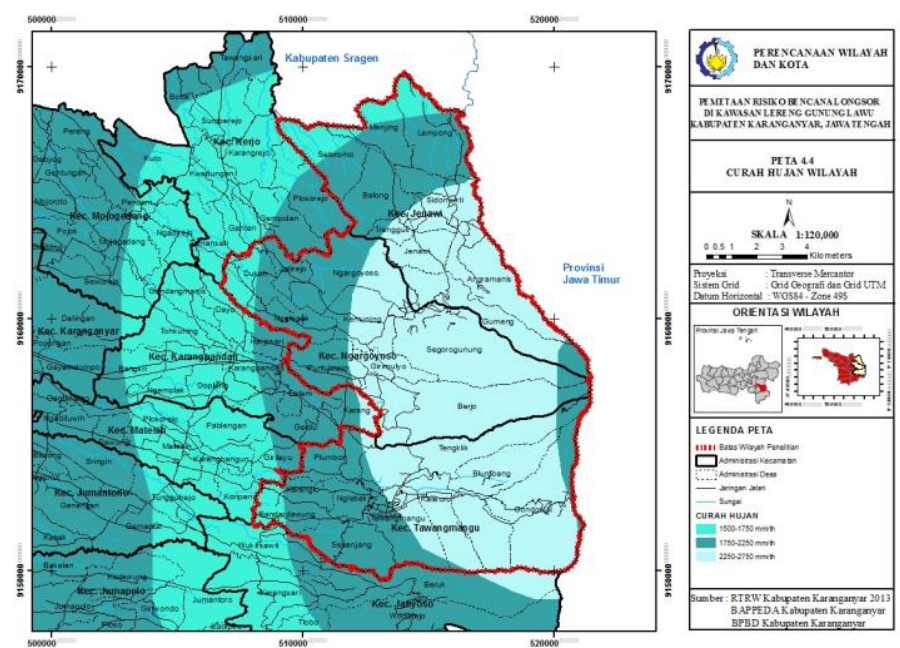

Gambar 5 Curah Hujan Wilayah

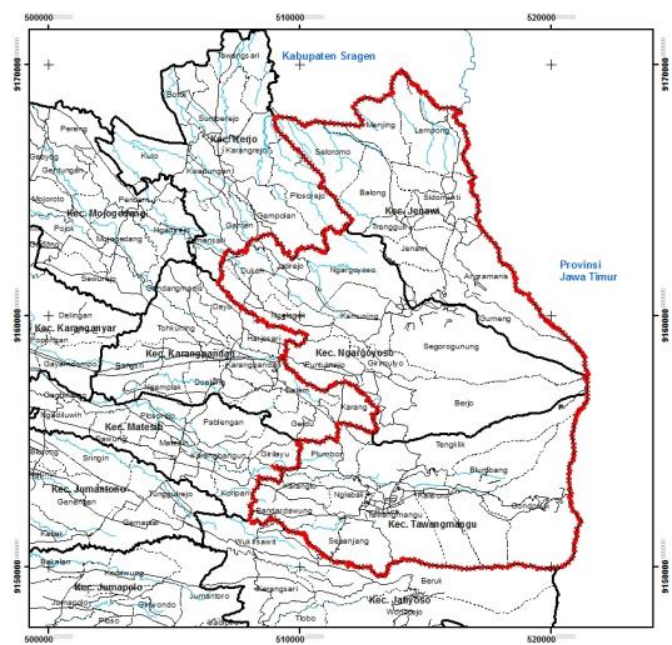

Gambar 6 Hidrologi Wilayah

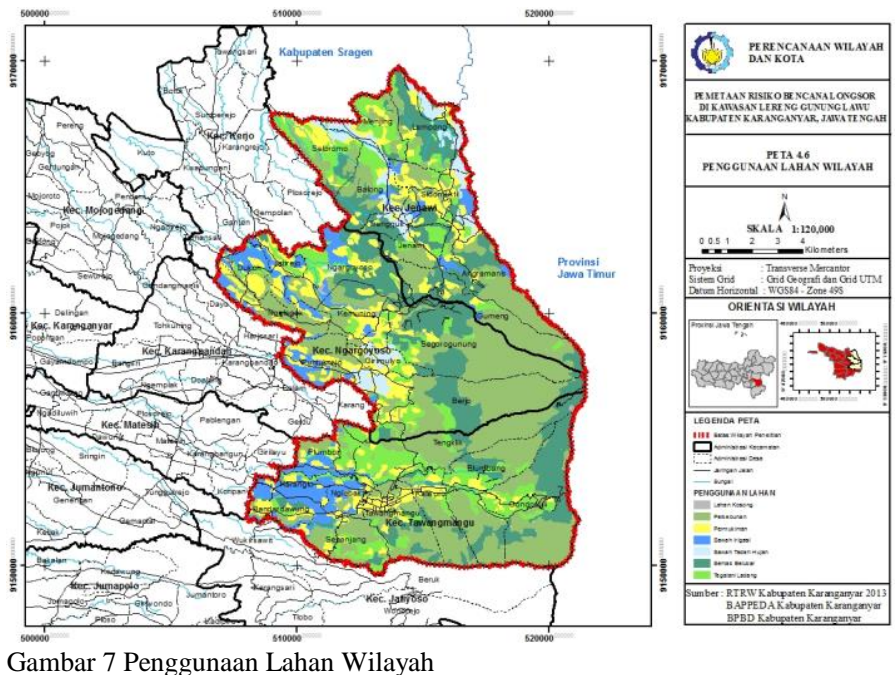

Setelah memperoleh bobot tersebut, dilanjutkan proses overlay weighted sum untuk mengetahui tingkat bahaya dilokasi penelitian. Dimana langkah awal dilakukan pengolahan dan input data, tahap ini digambarkan secara umum mengenai variabel-variabel tingkat bahaya longsor yang meliputi faktorfaktor penyebab bahaya longsor. Kemudian dilakukan raster pada masing-masing variabel. Selanjutnya dilakukan reclassify untuk mengkelaskan/menggolongkan data-data diatas yang dalam bentuk raster menjadi tingkatan tiap variabelnya. Pengkelasan masing-masing variabel telah dilakukan. Skala 1 menjukkukan tingkat rendah, skala 2 menunjukkan tingkat sedang, dan skala 3 menunjukkan tingkat tinggi. Setelah masing-masing variabel tingkat bahaya longsor yang di reclassify dan dilanjutkan zonasi untuk menentukan tingkat bahaya secara keseluruhan. Dimana pada proses ini dilakukan weighted sum dengan pembobotan yang telah dihasilkan menggunakan AHP. Adapun zonasi dari peta hasil analisis overlay tingkat bahaya longsor diperoleh 3 klasifikasi yaitu:

- Bahaya rendah ialah raster peta yang memiliki skor 1.28-1.51

- Bahaya sedang ialah raster peta yang memiliki skor $>1.51-1.92$

- Bahaya tinggi ialah raster peta yang memiliki skor $>1.92-2.49$

Berdasarkan hasil analisis overlay yang telah dilakukan, berikut rincian pembagian desa berdasarkan luas tingkat bahaya dapat dilihat dibawah ini:

Tabel 2

Pembagian desa berdasarkan luas tingkat bahaya

\begin{tabular}{llcccc}
\hline \multirow{2}{*}{ No. } & \multirow{2}{*}{ Nama Desa } & \multicolumn{3}{c}{ Persentase (\%) } & Tingkat \\
& & Rendah & Sedang & Tinggi & Bahaya \\
\hline 1 & Gumeng & 0,00 & 0,00 & 100,00 & Tinggi \\
2 & Anggrasmanis & 0,00 & 0,00 & 100,00 & Tinggi \\
3 & Jenawi & 0,00 & 0,00 & 100,00 & Tinggi \\
4 & Trengguli & 0,00 & 23,62 & 76,38 & Tinggi \\
5 & Sidomukti & 9,70 & 16,65 & 73,65 & Tinggi \\
6 & Balong & 0,09 & 71,90 & 28,01 & Sedang \\
7 & Seloromo & 0,00 & 92,88 & 7,12 & Sedang \\
8 & Menjing & 42,46 & 51,91 & 5,62 & Sedang
\end{tabular}




\begin{tabular}{llcccc}
9 & Lempong & 55,02 & 44,51 & 0,47 & Rendah \\
10 & Puntukrejo & 14,02 & 39,62 & 46,36 & Tinggi \\
11 & Berjo & 0,00 & 0,00 & 100,00 & Tinggi \\
12 & Girimulyo & 0,00 & 4,67 & 95,33 & Tinggi \\
13 & Segorogunung & 0,00 & 0,00 & 100,00 & Tinggi \\
14 & Kemuning & 0,86 & 31,45 & 67,69 & Tinggi \\
15 & Nglegok & 0,00 & 72,68 & 27,32 & Sedang \\
16 & Dukuh & 0,00 & 65,18 & 34,82 & Sedang \\
17 & Jatirejo & 0,00 & 35,85 & 64,15 & Tinggi \\
18 & Ngargoyoso & 0,00 & 34,20 & 65,80 & Tinggi \\
19 & Bandardawung & 0,00 & 79,61 & 20,39 & Sedang \\
20 & Sepanjang & 0,03 & 82,09 & 17,88 & Sedang \\
21 & Tawangmangu & 0,00 & 42,20 & 57,80 & Tinggi \\
22 & Kalisoro & 0,00 & 1,98 & 98,02 & Tinggi \\
23 & Blumbang & 0,00 & 0,40 & 99,60 & Tinggi \\
24 & Gondosuli & 0,00 & 12,23 & 87,77 & Tinggi \\
25 & Tengklik & 0,00 & 2,85 & 97,15 & Tinggi \\
26 & Nglebak & 2,28 & 49,19 & 48,53 & Sedang \\
27 & Karanglo & 3,59 & 96,41 & 0,00 & Sedang \\
28 & Plumbon & 17,12 & 64,49 & 18,40 & Sedang \\
\hline \hline
\end{tabular}

Sumber : Analisis, 2016

Berdasarkan analisis terdapat 17 desa yang memiliki tingkat bahaya tinggi antara lain :

1. Kecamatan Jenawi : Gumeng, Anggrasmanis, Jenawi, Trengguli dan Sidomukti

2. Kecamatan Ngargoyoso : Puntukrejo, Berjo, Girimulyo, Segorogunung, Kemuning, Jatirejo, dan Ngargoyoso

3. Kecamatan Tawangmangu : Tawangmangu, Kalisoro, Blumbang, Gondosuli, dan Tengklik

Untuk lebih jelasnya berikut gambar peta tingkat bahaya longsor di kawasan lereng Gunung Lawu

\section{KESIMPULAN}

Berdasarkan hasil analisis dan pembahasan yang telah dilakukan dalam penelitian, maka dapat disimpulkan bahwa tingkat bahaya pada kawasan penelitian diklasifikasikan menjadi 3 kelas yakni bahaya rendah, sedang dan tinggi. Dari klasifikasi tersebut didapatkan 17 desa yang memiliki bahaya tinggi. Tingkat bahaya yang sudah dihasilkan dapat digunakan sebagai lanjutan untuk merumuskan zona risiko bencana longsor di kawasan lereng Gunung Lawu, Kabupaten Karanganyar, Jawa Tengah.

\section{DAFTAR PUSTAKA}

[1] Pemerintah Republik Indonesia. 2007. Undang-Undang No. 24 Tahun 2007 tentang Penanggulangan Bencana. Jakarta: DPR RI.

[2] Dwikorita Karnawati. 2005. Bencana Alam Gerak Massa Tanah di Indonesia dan Upaya Penanggulangannya. Yogyakarta: Universitas Gajah Mada.

[3] Supriyono, Primus. 2014. Seri Pendidikan Pengurangan Risiko Bencana Tanah Longsor. Yogyakarta: ANDI OFFSET.

[4] Departemen Pekerjaan Umum. 2007. Peraturan Menteri Pekerjaan Umum Nomor : 22 /PRT/M/2007 Tentang Pedoman Penataan Ruang Kawasan Rawan Bencana Longsor. Jakarta: Dinas PU RI.

[5] Bappeda Kabupaten Karanganyar. 2015. Perda Rencana Tata Ruang Wilayah (RTRW) Kabupaten Karanganyar Tahun 2013-2032. Karanganyar : Bappeda Kabupaten Karanganyar.

[6] Prawiradisastra, S. (2008). Analisis morphologi dan geologi bencana tanah longsor di Desa Ledoksari Kabupaten Karanganyar. Jurnal Sains dan Teknologi Indonesia,10(2), 84-89.

[7] Chandra, R. K. dan Rima, D. S. 2013. Mitigasi Bencana Banjir Rob di Jakarta Utara. Diakses dari http://ejurnal.its.ac.id [Diakses 4 April 2013].

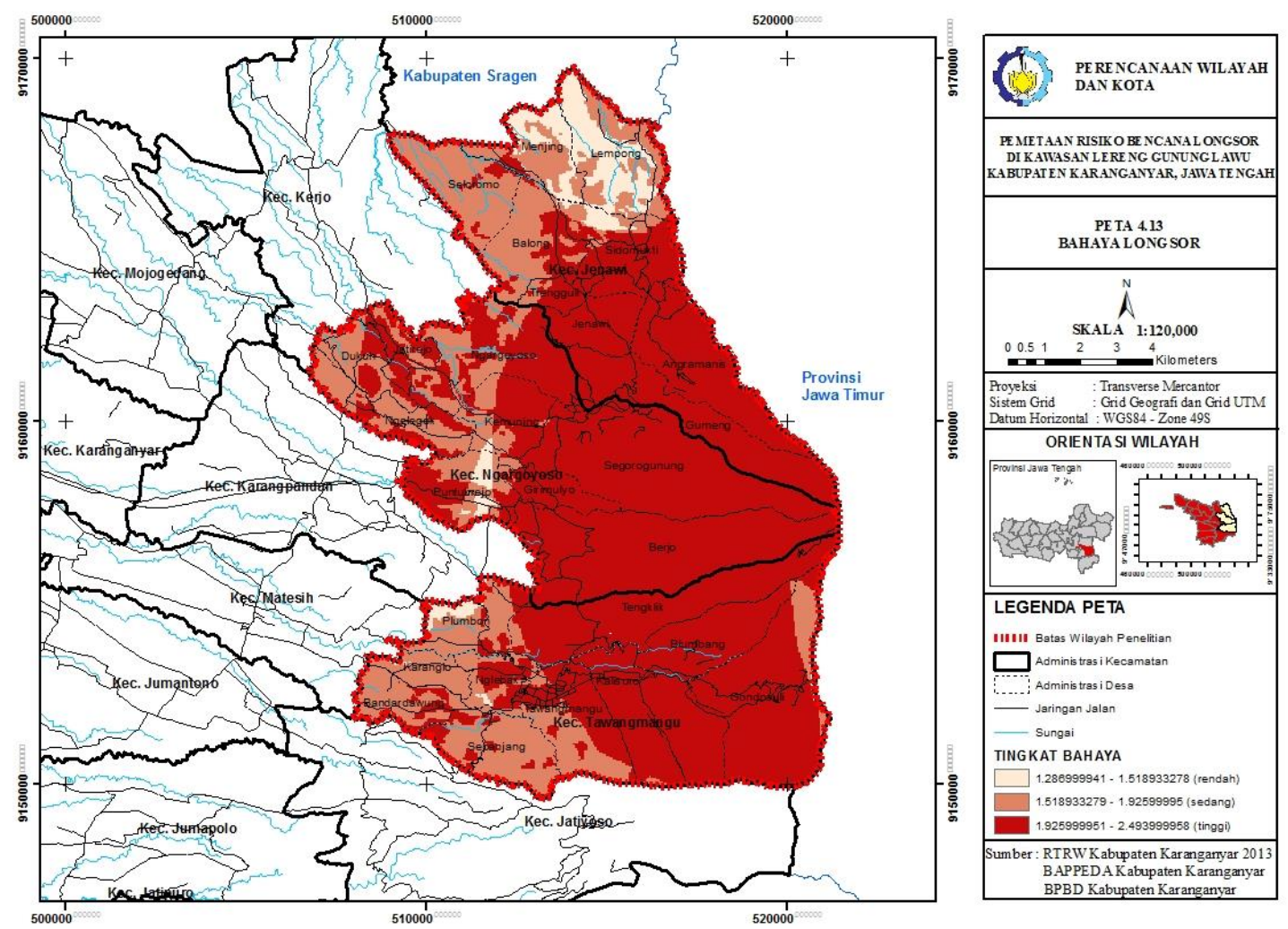

Gambar 8 Peta Bahaya Longsor 